\title{
ESTIMATION OF EVACUATION TIME OF PASSENGERS IN AIRCRAFT ACCIDENTS WITH FIRE IN AIRFIELD AREAS
}

\author{
Arthur SUHAREV (D)*, Vladimir SHESTAKOV D, Leonid VINOGRADOV \\ Riga Technical University, Institute of Aeronautics, 1 Lomonosova str., LV 1019, Riga, Latvia
}

Received 27 November 2019; accepted 29 April 2020

\begin{abstract}
Statistics show that the majority of aircraft accidents occurs in the vicinity of airfield areas. Yet the main factors leading to fatalities in these accidents are the forces encountered by human occupants in collision with obstacles and the presence of fire. It is possible to single out a group of "technically survivable" accidents from the total number of accidents, in which a crew member or passengers could have survived, if the evacuation took place in a timely manner. The share of such accidents is about $85-90 \%$. However, up to $40 \%$ of passengers die in technically survivable accidents. Applicable protection systems are only adequate, if the passengers manage to exit the airplane and get to a safe distance within a limited timeframe. Although these systems have been sufficiently developed; this is one of the most significant problems in modern aviation. This means, that the study of possibilities and the development of the methods and means of passenger evacuation in aircraft accidents, specifically in and around airport areas, are relevant to be addressed.
\end{abstract}

Keywords: aviation safety, aviation structures, aircraft layout, aircraft modeling, civil aviation, investigations.

\section{Introduction}

The characteristics of the Evacuation of Passengers in Aircraft Accidents in Airfield Areas. Aircraft accidents may be expected or sudden. The time factor is the main characteristic distinguishing one type of accident from another. The efficient use of available time in case of an expected accident, greatly increases the likelihood of saving lives of a much larger number of people. The evacuation capabilities depend on the class of aircraft, its cabin layout, total number of passengers, availability of emergency exits, and the time required for the operation of the latter. The crew and passengers have very little time left to leave the plane - from a few seconds to several minutes. This time depends on many factors; the appropriate training of the crew and instructions to the passengers, as well as the reception of timely notice by the search and rescue service all these activities contribute to reduce casualties. Aircraft rescue and emergency measures provided at an airfield should ensure immediate and effective arrangements for the rescue of passengers and aircraft crew in case of an aircraft accident within the airfield, along with evacuation of damaged aircraft in the event of undershoot, overshoot or excursion from the runway. This was discussed in ICAOMontreal, Quebec (2011).
The deployment time of rescue and emergency equipment is of critical importance. In practice, the deployment time has to be estimated in detail, by dividing it into constituent elements, to analyze the factors and "narrow" spots that affect this value (Bestreferat, 2009; Rogachev \& Veselago, 1981).

It is necessary to consider the possibility of panic and hysteria among the passengers. The discipline of the crew members and their ability to control the behavior of the passengers contribute to the survival of the latter. The aircraft commander should always be ready to take the necessary measures against the panic attacks and the lack of self-discipline among some passengers and even entire groups. This was discussed in Shestakov and Lazareva (2016). All of the above indicates the need to develop a comprehensive and feasibly constructed training program for flight crews and rescue and emergency services in order to prepare them for emergency procedures in case of an aircraft accident involving fire in the airport area (Rogachev, 1987; RIA, 2017). There are other studies about this subject mentioned in articles Avia.pro (2016), Holshevnikov et al. (2019), Goljashkin and Baranov (1990).

The development of fire scenarios may be various, nevertheless the deciding factor of survivability is the evacuation time. In this paper, an estimation of the deciding

*Corresponding author. E-mail: arturs.suharevs@gmail.com 
factor in the development of fire scenarios and the capacities of crews and airport services are presented.

\section{Possible fire situations and passenger evacuation scenarios}

It is impossible to have prearranged evacuation plans for all cases of aircraft crash landings. However, each crew prepares for such events by using the reference evacuation plans, based on the design features of the aircraft type for the following typical cases of emergency landings (ICAO Doc.9877, 1984):

1. Passenger evacuation from the aircraft on land in a normal landing configuration (landing gear fully extended) with the presence of a fire on both sides of the fuselage.

2. Passenger evacuation from the aircraft on land in case of a gear-up landing with the presence of a fire on both sides of the fuselage.

3. Passenger evacuation from the aircraft on water with the presence of a fire on both sides of the fuselage.

The evaluation of the existing emergency exits in an airplane (main, service doors, emergency hatches above (under) the wing, emergency hatches in the upper part of the cockpit and cabin, cockpit windows and cargo doors or hatches) can only be given if the following is considered; age, gender, physical condition and agility of each individual passenger and crew member participating in this flight or ground testing. Emergency hatches located above the wing and on the upper part of the aircraft fuselage may be of particular significance in case of an emergency landing on water.

\section{Statistical data on evacuation time of passengers from a burning aircraft in various scenarios}

This was discussed by Abashkin (2014) and Trudohrana (2020). The performance indicator of an evacuation process is the time during which the passengers and crew can leave the burning aircraft. This time is estimated from the moment of fire occurrence till the end of the evacuation process to a safe area. It can be divided into two parts the available time and the required time for evacuation. The available time is estimated from the moment of fire detection to the occurrence of dangerous impacts (factors) on passengers. The required time is the time from the moment of fire detection to the moment when the last person evacuates the aircraft and is at a safe distance. However, the moment of fire occurrence and the moment of fire detection may not coincide, and the evacuation in this case may be delayed. Currently, there are no standards for these indicators in the field of fire safety (ICAO Doc.9877, 1984; Vuzlit, 2019). Evacuation safety will be ensured, if the duration of the evacuation in total (the required time) is less than the duration of the fire after which it becomes a serious hazard to the passengers. Owing to the fact that not every exit from an airplane can provide a safe evacu- ation due to various types of possible situations, one must distinguish between the concepts of "evacuation exits" and "evacuation paths". This is particularly relevant for aircraft with large passenger capacity. The doorways, emergency exits, as well as cockpit windows, or hatches available in the aircraft structure should be referred to as evacuation exits. The evacuation paths in the burning cabin are such that they exclude, as much as possible, crowding and congestion of passengers on the way from the seats to the exits. The standard evacuation exits are demanded by applicable aircraft airworthiness requirements, and observance of the evacuation paths in the burning cabin is ensured by the training of flight and cabin crews. Numerous studies and works by various authors are devoted to evacuation and human behavior in fires and emergencies (ICAO Doc.9877, 1984; Avia.pro, 2016; ICAO Doc.9137, 2014; Wikidot, 2013).

\section{Experimental data analyses estimating the evacuation time of passengers from a burning aircraft shows that this is a random variable, which depends on numerous factors}

This was discussed by Vuzlit (2019), Avia.pro (2016) and ICAO Doc.9137 (2014). One of the most important indicators determining the rate of evacuation from an aircraft accident is the ratio of the number of passengers to the number of emergency exits. In case of any forced landing, expected or sudden, the choice of the exits for the passengers depends on; the degree of damage taken by the aircraft during landing, the position of the aircraft on land or on water after landing, as well as on the location of the seats of fire, the severity of the fire and the direction of its spread. According to ICAO requirements, the evacuation time, for any situation development, should not exceed 90 seconds through the half of the exits provided in the aircraft, which is the standard for aircraft manufacturers and rescuers. Therefore, in international practice, evacuation capabilities are estimated for various scenarios of aircraft on fire. There is no standard method for such estimations (Vuzlit, 2019). Depending on the circumstances during evacuation from the burning cabin of an airplane, all main, service and emergency exits can be used, as well as breaks in the fuselage, cockpit windows or hatches located in the cockpit. On the outer surface of the fuselage, the places for opening are marked with yellow angles on a white background, in order to avoid short circuits and arcing when opening the fuselage in arbitrary places that could cause an occurrence of an additional source of fire. Passengers are evacuated from a distressed aircraft under the control of crew members and use the exits that are indicated for them.

Passengers can also be characterized by physical conditions and degrees of mobility. Men aged 15-44 and women aged $15-26$ of age are generally physically stronger and more mobile than men aged 45-65 and women aged 2765. It should be noted that usually people over the age of 40 have a tendency to gain weight, to lose physical strength, and have weaker cardiac activity. Escaping from an 
airplane through the doors requires less physical strength and agility from the passengers than escaping through the windows. Doorways can be used by all passengers both in case of forced gear-up landing and gear-down landing, if a ladder, or an emergency slide is used at the exit. Overwing exits can be used by all passengers, except for obese and those with limited mobility. The window exits, located in front or behind the wings, can be used only by young and most mobile passengers, while other passengers, belonging to the age groups from 45 to 65 years (men) and from 27 to 65 years (women), can use these exits only in exceptional cases. The analysis of the data obtained from experiments and practice allows to make a comparative assessment of different types of exits in terms of the rate with which the passengers can leave the aircraft. If the rate of evacuation through the main doors is taken as 1 , then in comparison with this: the rate of evacuation through the overwing hatch can be estimated to 0.7 ; the rate of evacuation through the remaining hatches can be estimated to 0.4 . The tests, simulating an aircraft with gear-up landing, showed that the time required for one passenger to escape through the windows can be from 2 to 8 seconds, and the time required for one passenger to escape through the main doors can be from 1 to 1.25 seconds.

The real statistics can be assessed by the results of the testing (Vuzlit, 2019) in order to find out how long people can stay inside of a distressed airplane on fire, resulting from an accident. The obtained data showed that almost in all cases of fires (except for the strongest ones), the passengers have about 50 seconds to escape from the airplane. However, in some instances, when the fire penetrates the passenger cabin particularly quickly, the passengers must be able to leave the airplane in just 7.5 seconds. During the testing, in four cases of fires in simulated accidents, the passengers had 90-163 seconds to escape and in two cases, when the fuselage was covered by a fire, the passengers had 53 to 65 seconds to escape. In five out of the six cases under consideration, part of the passengers, depending on their location in the airplane, would have 93-257 seconds to escape. Thus, in case of a strong fire 90 seconds was enough for all passengers to escape in four cases, and for some of the passengers only in one case. Ninety seconds has been adopted by ICAO as the standard time allowing passengers to escape from an aircraft. A large number of passengers on board complicates quick evacuation from the airplane after a forced landing. As a result of a special testing, it was established that the evacuation of 60 passengers requires more time then the evacuation of 30 passengers, not twice as much, but considerably more time.

As a result of the experiments and the analysis of actual accidents, the time necessary to evacuate the maximum number of passengers from an aircraft in $2 \mathrm{~min}$. through each of the exits located on land (water) was also obtained (Vinogradov, Lazareva, \& Sestakovs, 2011):

1) through the doorway $(0.61 \mathrm{mX} 1.22 \mathrm{~m})-85$ people;

2) through the doorway $(0.51 \mathrm{~m} \mathrm{X} 1.12 \mathrm{~m})-55$ people;

3) through the over-wing hatch $(0.51 \mathrm{~m} \mathrm{X} 0.91 \mathrm{~m})-$ 25 people;
4) through the over-wing hatch $(0.48 \mathrm{~m} \mathrm{X} 0.70 \mathrm{~m})-$ 12-15 people.

The time required for a crew member to escape through the cockpit windows and the emergency hatch in the upper part of the fuselage of the aircraft (with the help of a life rope) is $25-30$ seconds. The time of installation and activation of an emergency escape slide is $40-50$ seconds, $20-25$ seconds of which are required for the slide to inflate. The time of installation and activation of the fabric escape chute is 50-60 seconds, including the time for two people to slide down first and secure the chute for other passengers, which is $15-20$ seconds.

\section{Analysis of the methods estimating the evacuation time of passengers from a burning aircraft}

There are different approaches to assess evacuation time from burning premises. The choice of a mathematical model for estimation of the evacuation time is made considering the specific features of the space-planning solutions of the object on fire, the homogeneity of people, the area of the horizontal projections of people on site, and the parameters of people movement with different mobility groups (Nisula, 2009; Mark \& Glen, 1995).

Considering the above mentioned, the evacuation time could be determined by using both simplified and rather sophisticated models. The use of simple or sophisticated models is determined by the goals of the tasks being solved and the necessary accuracy of the provided results.

The most widespread models for the assessment of fire risks are the following:

1) simplified analytical model; estimation according to a simplified mathematical model is the least effective, the obtained results are very coarse, since a number of features of the human movement flows are not taken into account.

2) stochastic model (model ADLPV). This model is considerably more accurate by means of the division of the object into elementary areas and further complication of the estimation operations. However, the consideration of individual characteristics of the passengers is difficult for this model; yet, this circumstance is very important for the evacuation from the burning cabin of an aircraft.

3) individually-flow model. This model is characterized by many calculations. For instance, it may be used for control estimations on a modern aircraft of large capacity.

The basic parameters when using any of the listed models are the following:

1) density of a human flow (D);

2) rate of movement of a human flow (v);

3) capacity of a path $(\mathrm{Q})$;

4) intensity of movement (q);

5) length of an evacuation path, both horizontal and inclined (1);

6) width of an evacuation path. 


\section{Density of human flow}

The density of a human flow can be measured in different units. Density measured by distance per person is usually called linear and is measured in $\mathrm{m} /$ person. A more evident unit of measurement of the density of a human flow is the density in relation to the area unit of an evacuation path and expressed in person $/ \mathrm{m}^{2}$. The flow density is also measured as the ratio of the part of the path occupied by people to the total area of the path. This value characterizes the degree of occupation of the evacuation paths by evacuees. The concept of the estimated density of a human flow is introduced for the estimation of evacuation, which means the maximum value of density when moving in any part of the evacuation path. The maximum possible density is the limiting value, which implies the density value, that cannot be exceeded, otherwise a physical damage to a human body or asphyxia can be caused.

1. The rate of a human flow. The used estimated rate, that is legalized by design standards for the premises with a mass presence of people, is $16 \mathrm{~m} / \mathrm{min}$. The examination of the flow rates at ultimate densities have shown that the minimum rates on the horizontal sections of a path are ranging from 15 to $17 \mathrm{~m} /$ min. It is obvious that the determination of this rate for aircraft has its own characteristics.

2. The specific exit capacity rate. The specific exit capacity rate implies the number of people passing through an exit of 1 meter in width in 1 minute.

3. The minimum value of the specific capacity, obtained experimentally, at a given density is called the estimated specific capacity. The specific capacity of emergency exits depends on the width of the exits, densities of the human flow, and the ratio of the width of the human flow to the width of the exit.

4. The dimensions of emergency exits. The dimensions of the evacuation paths and exits of an aircraft depend on the type of the aircraft.

\section{Estimation of the evacuation time of passengers from SSJ-100, a modern short-haul aircraft, in case of different fire scenarios and number of used exits}

In this section, authors have used the generally accepted methodology of human flow evaluation during evacuation from a burning building and adopted it to human flow from a burning aircraft and used for concrete calculations.

By comparing different models for the estimation of the evacuation time in case of an aircraft accident, it can be concluded that the simplest analytical model of the human flow movement will be the most acceptable for this estimation. The main conditions of this method are the following with respect to aircraft (Nisula, 2009).

The estimated time for the evacuation of people $t_{\mathrm{p}}$ is determined by estimation of the human flow movement time through evacuation exits from the most remote passenger locations. When estimating the entire path of the human flow movement, we subdivide it into sections: passages, evacuation exits and the aisle path. The slide is considered an independent section of the horizontal path with a final length $\boldsymbol{l}_{i}$ and width $\delta_{i}$. The initial sections are the passages between the rows of seats, equipment, etc. When determining the estimated time, the actual length and width of each section of the evacuation path should be taken into account; the length of the path along the slide, as well as the evacuation hatches along the inflatable slides - by their dimensions. The estimated time for the evacuation of passengers $t_{\mathrm{p}}$ is defined as the sum of the human flow movement time along separate sections of the path $\boldsymbol{t}_{\boldsymbol{i}}$ by the formula:

$$
t_{p}=t_{1}+t_{2}+t_{3}+, \ldots,+t_{i},
$$

where: $t_{1}$ - time of the human flow movement at the first (initial) section, $s ; t_{2}, t_{3}, \ldots, t_{i}$ - time of the human flow movement at each of the following sections after the first section of the path, $s$.

Time of the human flow movement is estimated by the formula:

$$
t_{1}=\frac{l_{1}}{v_{1}},
$$

where: $l_{1}$ - length of the first section of the path, m; $v_{1}, \mathrm{~m} / \mathrm{sec}$ - the rate of the human flow movement, $\mathrm{m} / \mathrm{sec}$ is taken from the reference table, depending on the density D. At the same time, we accept the flow density of 0.9 or more.

The specification of the homogeneous human flow density can be estimated by the formula:

$$
D_{1}=\frac{N_{1} f}{l_{1} \delta_{1}}
$$

where: $N_{1}$ - number of passengers in a section, people; $\delta_{1}$ - width of the path section, $\mathrm{m} ; f$ - average area of a person's horizontal projection, $\mathrm{m}^{2} /$ person. The value is taken from the reference tables for different categories of people:

adult without outer clothing -0.1 ;

adult in the outer clothing -0.125 ;

teenager -0.07 .

The value of the evacuation start time $\boldsymbol{t}_{\text {s.e. }}$ for the aircraft is estimated from the results of the study of the behavior of passengers in case of fire on the airplane of a particular purpose. Numerous cases from the practice of passenger evacuation from the airplane show that the estimation of the average distance from a passenger seat row to the exit $L_{e v}$ and the distance from the seats to the pass, as well as the time for preparation of the emergency evacuation equipment $t_{e v}$, and the capacity of the exits $V_{e v}$ are of critical importance for the estimation of the evacuation time. The time for general evacuation will depend on the adopted evacuation method: through the doors with inflatable slides, through hatches, etc. It is necessary to determine their capacity in all cases, i.e. the average rate of evacuation from the airplane of one person through each of the exits separately. The time for preparation of 
the passengers to the escaping can supplement the time of general evacuation only if the capacity of all exits is greater than the rate of the passengers' movement in the cabin. Evacuation should be based on the number of people going through each exit. It should be simple, without counter flows, with a uniform load on the exits. It should be noted that in accordance with the special behavior of the passengers in an emergency, it is necessary to enter the delay in the evacuation time for a psychological reaction. The final formula, considering the aforesaid, as well as the characteristics of the evacuation from the burning airplane, is the following (Vuzlit, 2019):

$$
\begin{aligned}
& T_{\text {ev.vid. }}=t_{d}+t_{l}+t_{r}+\frac{t_{p . t r .}}{n_{\text {izk.kop. }}}+n_{p . t r .} \cdot V_{\text {ev.sag.p.tr. }}+ \\
& l_{n p . t r .}+n_{r .} \cdot V_{\text {ev.sag.r. }} \cdot l_{n r .}+n_{\text {v.tr. }} \cdot V_{\text {ev.sag.v.tr }}+ \\
& \frac{n_{l .} \cdot V_{\text {ev.sag.l. }} \cdot l_{n l .}}{n_{\text {izk.kop. }}}
\end{aligned}
$$

where: $t_{d}, t_{l}, t_{r}, t_{p . t r},-$ the time for preparation of the doors, hatches, riffles, inflatable slide for the evacuation process. $n_{i z k . k o p .,} n_{p . t r}, n_{r .}, n_{v . t r}, n_{l}-$ the total number of exits; the number of exits, which have inflatable slides; the number of exits which have riffles; the number of exits which have escape hatches; the number of special emergency exit hatches. $l_{n p . t r,} l_{n r .,} l_{n v . t r .}, l_{n l}$ - the number of evacuated people by inflatable slides; the number of people evacuated by riffles; the number of people evacuated by rope ladders; the number of people evacuated by hatches.

$V_{\text {ev.sag.p.tr., }} V_{\text {ev.p.tr. }}, V_{\text {ev.r. }}, V_{\text {ev.v.tr., }} V_{\text {ev.l. }}, V_{\text {vid. }}$ - the rate of evacuation during the defined time; the rate of evacuation by inflatable slides; the rate of evacuation by riffles; the rate of evacuation by rope ladders; the rate of evacuation by hatches; the average rate at which the transition from passenger seats to the exits takes place.

$L_{v i d .}$ - the average distance between the rows of seats and exits;

$t_{\text {ev.sag. }}$ - the preparation time for evacuation;

$V_{\text {ev.sag. }}$ - permeability of exits at evacuation;

The following values are being determined experimentally:

$V_{\text {ev.sag. }}$ - the permeability of exits at evacuation;

$t_{\text {ev.sag. }}$ - the preparation time for evacuation;

The preparation time for completion of the phase until the corresponding exit is being similarly defined.

The time needed for the preparation of the passengers for the evacuation may supplement the total evacuation time only if the capacity of all exits is greater than the passenger movement rate in the cabin.

In accordance with the certification rules, the ground tests (Wikidot, 2013) are conducted in the presence of the experts with the use of objective control means of the emergency evacuation, in order to demonstrate that in case of an emergency landing, all passengers on board, as well as all crew members are successfully evacuated within 90 seconds (the standard established by ICAO for such situations). People of different age groups are involved in these tests. However, in practice, the situation can radi- cally differ from the standard one (Figure 1), which was examined during the certification tests, and therefore the evacuation time will also be different and not always complying with the ICAO standard.

The circumstances under which aircraft accidents with a fire occur in the airport area can be various, and airplanes can be equipped in different ways. Exits in the airplane cannot be considered equal, since some of them, for example, due to proximity to fuel tanks, are less reliable. In case of an emergency landing on land, separate exits will be restricted due to deformation of the airplane on impact with the ground, the proximity of fire points to the exits or the presence of the obstacles on the ground. Therefore, it is very difficult to develop and to have the entire set of possible scenarios for the escaping of the passengers from an airplane in advance for all the cases mentioned above.

By using the above mentioned simplified analytical model of the human flow, we should calculate the passenger evacuation time for the scenarios mentioned in the ICAO Airport Services Manual.

Passenger evacuation from the airplane under consideration can be carried out through four doors - A and four over-wing hatches - B (Figure 2). During the certification tests, the evacuation of 90 people through the four doorways took 73 seconds, which is significantly lower than the standard of 90 seconds (Wikidot, 2013).

The initial data on the passengers adopted during the certification tests were used for the estimation. The number of people is 90 . The typical composition of the passengers with normal health in the following ratio:

1. $30 \%$ women; $5 \%$ people over 60 years of age with a proportional number of women;

2. 5\% children under 12 years of age, evenly distributed by age. The average rate of human movement is $1.3 \mathrm{~m} / \mathrm{s}$;

Fragment of the estimation.

The time of escaping from the cabin is divided into two parts:

1) the time for running to emergency exits (EE);

2) the time for escaping from EE is adopted according to the standards of the technical documentation.

It is assumed that the passengers are distributed evenly across EE, i.e. between EE along the planes of symmetry of the airplane cabin.

The estimation of the evacuation time of passengers is started by obtaining the complete geometric parameters of the aircraft fuselage (cockpit and passenger cabin), using the design documentation. These parameters include:

1) number of emergency exits;

2) number of seats in the cabin;

3) number of rows of seats;

4) number of seats in a row;

5) distance between the rows;

6) width of the passes and their number;

7) distance from the outermost rows of seats to emergency exits (EE);

8) diameter of the fuselage;

9) length of the passenger cabin. 


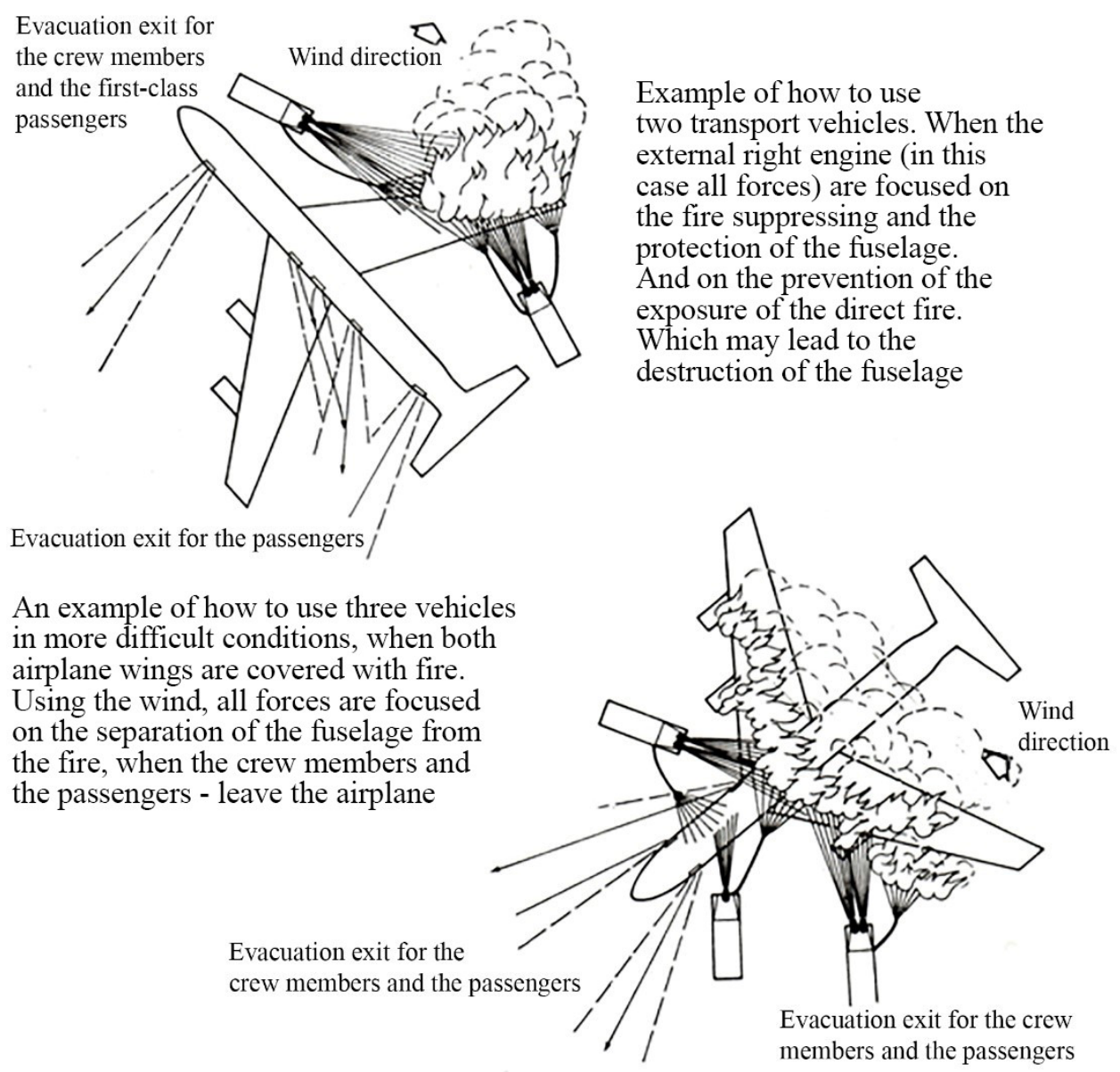

Evacuation exit for the crew members and the first-class passengers

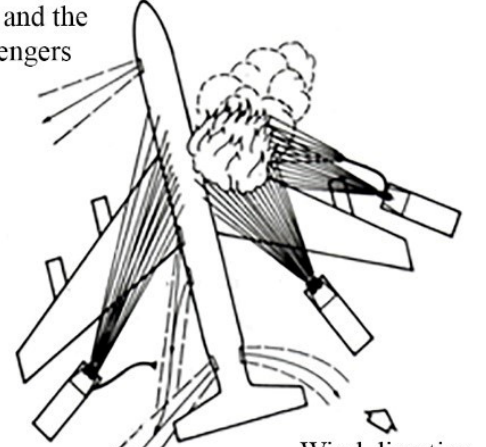

Example of how to use three basic vehicles that pour the foam during a fire into the opening part of the wing at the sidewind. If the left engine continues to operate. The fire suppression should be transferred to the opening part of the wing

Wind direction

Evacuation exits for the passengers

Example of how to use three basic vehicles when the key requirement is the maintenance of the integrity of the internal left engine and the fuel tank area in order to enable evacuation

Evacuation exits for the passengers

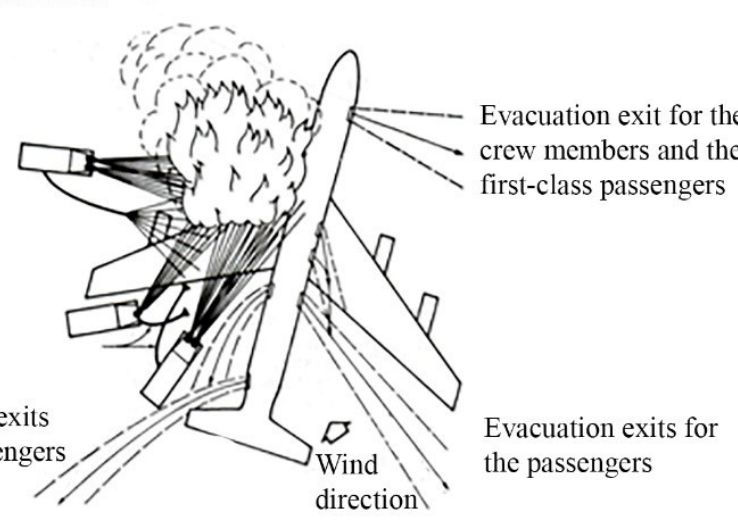

Figure 1. Possible situations related to airplane in case of accidents with fire and evacuation scenarios (ICAO-Montreal, 2011) 
The layout of the passenger cabin of this type of airplane in emergency, is depicted in Figure 3 and Figure 4. The geometric characteristics are the following:

1) seat width;

2) seat pitch;

3) half the width of the aisle.

The certain number of exits according to the Table 1 are used for each version. The results are presented in the last column.

The estimation for version 1 is based on the data:

1) seat width + half the width of the aisle + seat pitch (length of the pass) + EE.

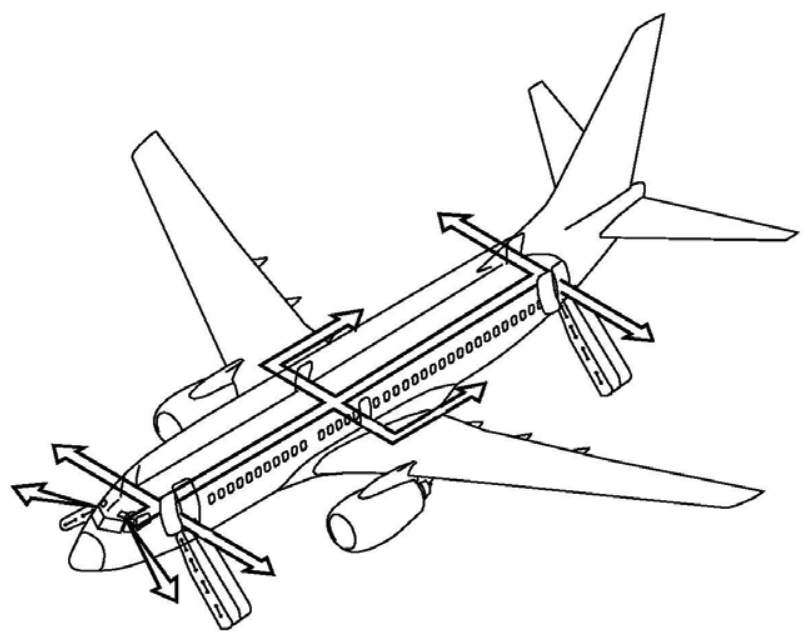

Figure 2. Short-haul passenger airplane of SSJ-100 type
Fragment of the estimations:

Seat No. 6A to EE1:

$\mathrm{X}=$ seat width + half the width of the aisle + seat pitch $+($ seat width $\cdot 2) \cdot 1.3+$ EE1 $=(0.45+0.47+0.81+$ $0.9) \cdot 1.3+1=4.416 \mathrm{sec}$.

Seat No. $7 \mathrm{~B}$ to EE1:

$\mathrm{X}=$ half the width of the aisle + seat pitch + (seat width $\cdot 2) \cdot 1.3+\mathrm{EE} 1=(0.47+0.81+0.9) \cdot 1.3+1=3.834 \mathrm{sec}$.

Seat No. $8 \mathrm{C}$ to EE2:

$\mathrm{X}=$ half the width of the aisle + seat pitch + (seat width $\cdot 3) \cdot 1.3+$ EE2 $=(0.47+0.81+1.35) \cdot 1.3+1=$ $4.419 \mathrm{sec}$. etc.

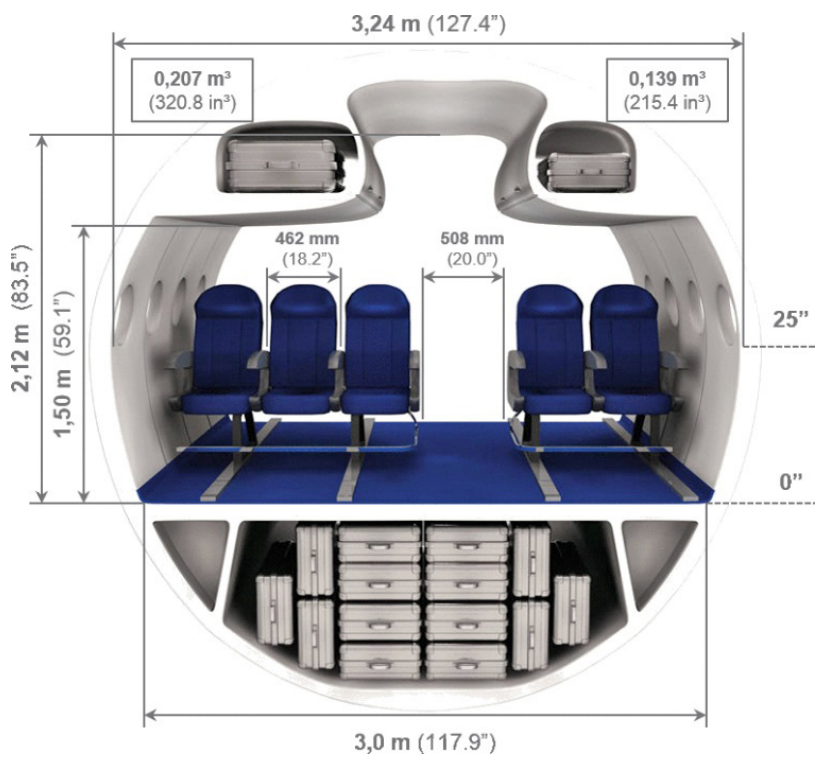

Figure 3. Cabin parameters of the aircraft of SSJ-100 type

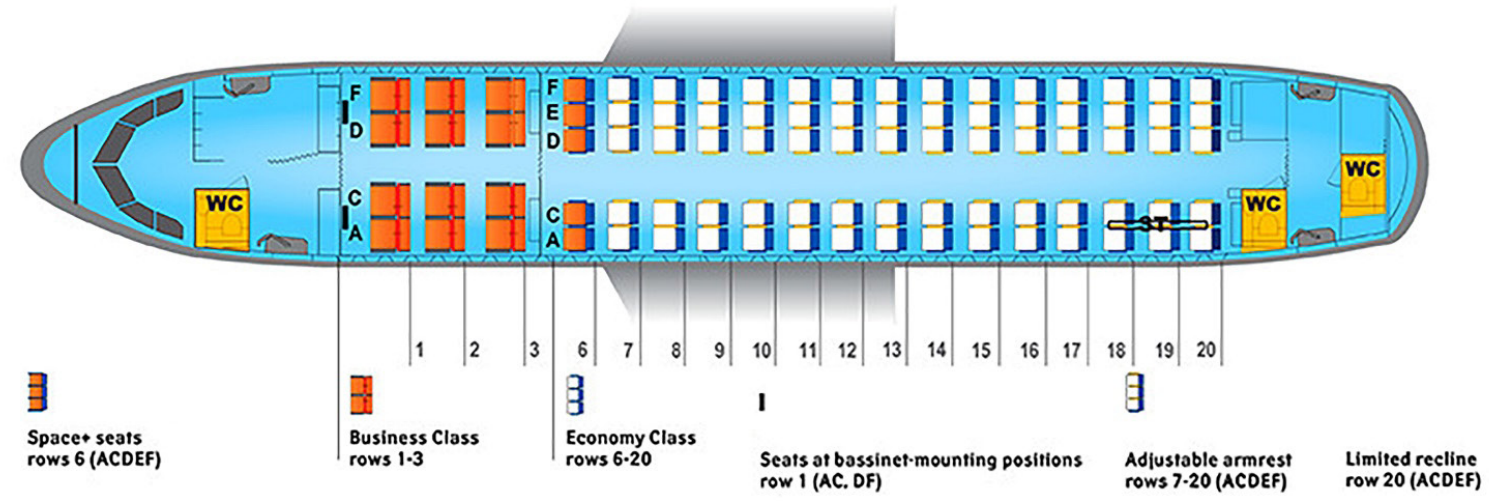

Figure 4. Design Model of the aircraft of SSJ-100 type

Table 1. Number of properly functioning emergency exits

\begin{tabular}{|c|c|l|c|l|c|c|}
\hline Nr. & $\begin{array}{c}\text { Cockpit } \\
\text { windows }\end{array}$ & \multicolumn{1}{|c|}{ Front doors } & $\begin{array}{c}\text { Over-wing } \\
\text { hatches }\end{array}$ & \multicolumn{1}{|c|}{ Rear doors } & $\begin{array}{c}\text { Emergency } \\
\text { exits in total }\end{array}$ & $\begin{array}{c}\text { Time of evacuation, obtained } \\
\text { from estimations, sec }\end{array}$ \\
\hline 1 & N/A & One on the right & Two on the right & One on the right & 4 & 62 \\
\hline 2 & both & $\begin{array}{l}\text { Both (on the right }- \text { on } \\
\text { the left) }\end{array}$ & N/A & $\begin{array}{l}\text { Both (on the right }- \\
\text { on the left) }\end{array}$ & 5 & 92 \\
\hline 3 & N/A & One on the right & N/A & $\begin{array}{l}\text { Both (on the right }- \\
\text { on the left) }\end{array}$ & 3 & 95 \\
\hline 4 & N/A & One on the left & Two on the left & One on the right & 4 & 95 \\
\hline
\end{tabular}


Table 2. Time of running to $\mathrm{EE}$ in the table

\begin{tabular}{|c|c|c|c|}
\hline Seat No. & Time, $s$ & Place No. & Time, $s$ \\
\hline A-1 & 2.6 & A-86 & 2.6 \\
\hline B-2 & 2.8 & B-87 & 2.8 \\
\hline C-28 & 8.6 & C-63 & 8.6 \\
\hline
\end{tabular}

Fragment of the estimation of the time of running to the exit in the Table 2.

The control time for the running to an emergency exit is the maximum time from the estimations - $12.9 \mathrm{sec}-$ onds. The results of the estimation show that in the event of an emergency landing of a version 1 SSJ-100, all passengers and crew members can leave the airplane within 62 seconds. The estimations for the remaining versions also were satisfactory and are almost close to the ninetysecond standard established by ICAO.

\section{Conclusions}

1. The procedure for the evacuation of people from burning objects showed that a simplified analytical model can be used with respect to civil aircraft, which takes into account the specifics of possible scenarios of aircraft accidents and the estimation of its participants in a theoretical and experimental way. In this case, it is important to study the time required for evacuation $\boldsymbol{t}_{\mathrm{p}}$ in detail - under different scenarios of the situation development, its division into constituent elements and the acquisition of a visual picture of the factors and "narrow" spots that affect this value, which is the basis for improvement of all elements affecting the survival of people under such conditions.

2. The results of the estimation show that the time of emergency escaping from the aircraft of SSJ-100 type in the cases considered is complying with the standards set by ICAO or is very close to the standards, and confirm that in case of emergency landing all passengers of the aircraft and the crew members will have time to leave the airplane before the occurrence of the critical conditions inside the cabin.

3. The results of the research showed that the used methodology adapted to aviation scenarios could be used to all future and existing aircraft for estimation of the evacuation time of passengers in an accident. In the next article these results will be compared with other methods to determine which method is preferable to be used in certain situations or aircraft types.

\section{References}

Abashkin, A. (2014). Posobie po primeneniju metodiki rascheta pozarnogo riska. http://legalacts.ru/doc/posobie-po-primeneniiu-metodiki-opredelenija-raschetnykh-velichin/

Avia.pro. (2016, January 01). Evakuacija pasazhirov iz samoleta. http://avia.pro/blog/evakuaciya-passazhirov-iz-samoleta

Bestreferat. (2009, July 21). Accidents and evacuation of passengers from an aircraft. https://www.bestreferat.ru/referat-102777.html

Fireexpo. (2017, December 11). Metodika opredelenija velichini pozarnogo riska $v$ objektah razlichnih klassov pozarnoj opasnosti. http://fireexpo.ru/obespechenie-pozharnoj-bezopasnosti-o/ob-utverzhdenii-metodiki-opredelenija-4.html

Goljashkin, V., \& Baranov, S. (1990, December 11). Rekomendaciji po tusheniju pozharov na vozdushnih sudah na aerodromach grazdanskoj aviaciji. http://pozhproekt.ru/nsis/Rd/ Rekom/rek-tushenie-aerodrom.htm

Holshevnikov, V., Samoshin, A., Istratov, N., \& Sharanova, M. (2019). Testovie zadachi dlja proverki tochnosti modelirovanija vremeni evakuaciji ljudej v sluchae pozhara. Akademija GPS MCS Rossii.

ICAO-Montreal, Quebec. (2011). A coordinated, risk-based approach to improving global aviation safety/2011 state of global aviation safety. Canada.

ICAO Doc.9877. (1984). Airport Services Manual.

ICAO Doc.9137- AN/898 Part 1. (2014). Aiport Services Manual Part 1 Rescue and Fire Fighting Fourth Edition.

Mark, A., \& Glen, M. (1995). National Aeronautics and Space Administration of the USA, National Plan for Civil Aviation Human Factors. https://ntrl.ntis.gov/NTRL/dashboard/ searchResults/titleDetail/PB95185518.xhtml

Nisula, J. (2009, June 09). Operational risk assessment. Next generation methodology. https://skybrary.aero/bookshelf/books/694.pdf

Ria. (2017, January 16). Krupnie aviakatastrofi v mire v 2015-2017 godah. https://ria.ru/spravka/20170116/1485749330.html

Rogachev, A., \& Veselago. V. (1981). Obespechenie bezopasnosti passazirov pri aviacionnih proisshestvijah s pozarami. Problemi bezopasnosti poletov (pp. 74-81). Moscow.

Rogachev, A. (1987). Efektivnostj tushenija pozarov vozdushnih sudov pri aviacionnih proisshestvijah. Problemi bezopasnosti poletov (pp. 78-88). Moscow.

Shestakov, V., Lazareva, I. (2016). Guidelines on evaluating passenger evacuation possibilities in aviation incidents involving fires. Aviation, 20. https://doi.org/10.3846/16487788.2016.1195063

Trudohrana. (2020, February 28). Raschet pozarnogo riska. https://www.trudohrana.ru/article/100001-qqq-17-m9-raschet-pojarnogo-riska

Vinogradov, L., Lazareva, I., \& Sestakovs, V. (2011). Fuselage cladding fire resistance assessment of aviation accidents with (pp. 320-325). RTU Izdevnieciba.

Vuzlit. (2019, December 18). Evakuacija passazhirov iz samoleta na sushe v uslovijah pozhara. https://vuzlit.ru/1017707/ evakuatsiya_passazhirov_samoleta_sushe_usloviyah_pozhara

Wikidot. (2013 March 04). Ispitanija i sertifikacija superjet. http://superjet.wikidot.com/test 